\title{
DEMONSTRANDO OS FUNDAMENTOS, POTENCIALIDADES E LIMITAÇÕES DA ANÁLISE POR INJEÇÃo SEQÜENCIAL
}

\author{
Jorge Cesar Masini \\ Instituto de Química, Universidade de São Paulo, CP 26077, 05513-970 São Paulo, SP - Brasil
}

Recebido em 13/7/07; aceito em 20/9/07; publicado na web em 19/3/08

\begin{abstract}
DEMONSTRATING THE FUNDAMENTALS, POTENTIALITIES AND LIMITATIONS OF SEQUENTIAL INJECTION ANALYSIS. The sensitivity and accuracy of sequential injection methods are dependent on efficient overlapping of reagent and sample zones as they are propelled toward the detector cell. The formation of the reduced phosphomolybdic acid is used to demonstrate that the overlapping efficiency in a fixed reaction coil relies on a suitable choice of reagent to sample volume ratio. Additionally, under poor mixing conditions or highly concentrated samples, the reaction extension is strongly dependent on the reagent concentration. The zone-sampling concept is exploited to determine phosphate in cola-based soft drinks after in-line dilution in an auxiliary coil.
\end{abstract}

Keywords: sequential injection; spectrophotometry; phosphate.

\section{INTRODUÇÃO}

Análise por injeção seqüencial (SIA, Sequential Injection Analysis) é considerada a segunda geração de sistemas de Análise por Injeção em Fluxo (FIA). ${ }^{1}$ Foi concebida em 1990 no sentido de simplificar mecanicamente os sistemas FIA, facilitando a implementação dos métodos em fluxo no monitoramento on-line de processos industriais, onde robustez, estabilidade por longos períodos, baixa necessidade de manutenção, calibração automática e automação são requisitos essenciais. ${ }^{2,3}$

Os princípios de injeção da amostra, dispersão controlada e alta precisão dos tempos de reação são comuns ao FIA e ao SIA. ${ }^{3}$ A instrumentação em um sistema SIA consiste de uma bomba de pistão (ou peristáltica), uma única linha de transmissão e uma válvula seletora. Esta válvula é o componente principal do sistema, contendo de seis a dez portas, além de uma porta central, que tem acesso a cada uma das outras com a rotação da válvula. A ligação da válvula ao sistema de propulsão de líquidos é feita com uma bobina coletora conectada na porta central da válvula seletora. As outras portas desta válvula são conectadas a reagentes, amostra, padrões, detector, bobinas auxiliares, reservatório para acúmulo de resíduos, etc. Um computador comanda a bomba e a válvula com um software apropriado para controle sincronizado do movimento de ambos, assim como a aquisição de dados do detector. Durante uma análise, volumes pré-determinados de reagentes e amostra são aspirados seqüencialmente para o interior da bobina coletora. Revertendo-se a direção do fluxo, a zona de amostra é transportada em direção à cela de detecção através de uma bobina de reação, onde a sobreposição das zonas ocorre por uma combinação de efeitos de dispersão axial, dispersão radial e difusão., Ao contrário dos sistemas FIA, nos quais a adição de reagentes pode ser feita por confluência, ${ }^{5,6}$ nos sistemas SIA a mistura só se dá pelos processos de dispersão e difusão. ${ }^{3}$ Com isso a extensão com que a reação procede depende, além do tempo de residência no sistema, do grau de sobreposição das zonas de reagente e amostra, o que requer um cuidadoso estudo das relações de volume utilizadas, bem como das concentrações dos reagentes, no sentido

*e-mail: jcmasini@iq.usp.br mantê-los em excesso em relação à quantidade estequiométrica na zona de reação. Além disso, parâmetros clássicos tais como diâmetro, comprimento e geometria do reator também influenciam a sobreposição das zonas.

Fixando-se as dimensões e a geometria do reator, o grau de sobreposição de duas zonas adjacentes em um sistema SIA pode ser avaliado injetando-se corante no lugar de reagentes e amostra, registrando-se o sinal correspondente dos gradientes de concentração e sobrepondo-os em um mesmo gráfico, como mostrado na Figura 1. O grau de sobreposição $(P)$ é definido pela expressão: ${ }^{3,4}$

$$
P=\frac{2 W_{0}}{\left(W_{A}+W_{R}\right)}
$$

onde $W_{A} e W_{R}$ são as larguras de pico na linha de base dos gradientes de concentração da amostra e reagente, respectivamente, enquanto $W_{0}$ é a largura da região de sobreposição das zonas. Quando $\mathrm{P}=1$ ocorre completa sobreposição das zonas, porém quando $\mathrm{P}=0$ não existe sobreposição. Na ausência de sobreposição completa observa-se um ponto de isodispersão no qual os coeficientes de dispersão da amostra e do reagente são idênticos, de modo que a razão das concentrações é igual à das soluções puras antes de serem injetadas no sistema.

No presente artigo a reação de formação do azul de molibdênio, classicamente utilizada para determinação espectrofotométrica de fosfato, foi explorada no sentido de ilustrar o efeito do volume de amostra e concentração de um dos reagentes (molibdato de amônio) na magnitude do sinal analítico e na linearidade da curva analítica. Adicionalmente, o conceito de reamostragem ${ }^{7}$ foi utilizado para efetuar diluição em linha de amostras concentradas visando a determinação de fosfato em refrigerante.

\section{PARTE EXPERIMENTAL}

\section{Aparelhos e reagentes}

Em todos os experimentos utilizou-se o equipamento FIALab 3500 da FIALab Instruments (Bellevue, WA, USA) montado conforme descrito na Figura 2. As soluções foram impulsionadas atra- 
vés do sistema com uma bomba de pistão (BP). O direcionamento e seleção das soluções através do sistema foi obtido utilizando-se uma válvula rotatória seletora (VR) de oito portas da Valco Instrument Company (Houston, TX, USA).

A bobina coletora (BC) foi construída com um tubo de Teflon de $3 \mathrm{~m}$ de comprimento e diâmetro interno de $0,8 \mathrm{~mm}$. A bobina de reação (BR) também foi feita com tubo de Teflon, mas com di-

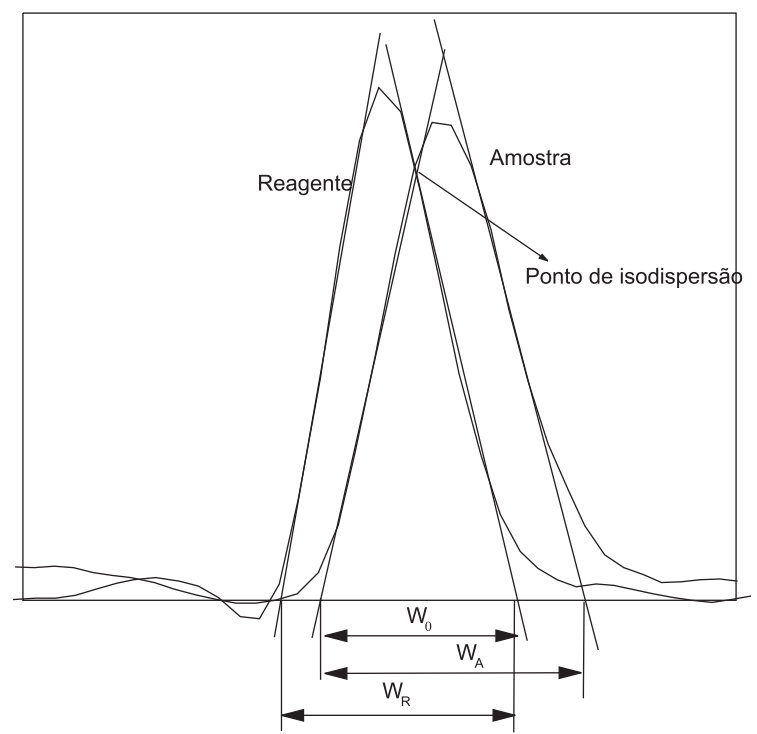

Figura 1. Diagrama ilustrando os gradientes de concentração correspondentes à injeção de duas zonas adjacentes em um sistema SIA. No presente caso a amostra é injetada primeiramente na bobina coletora, seguindo-se o volume de reagente. Como o reagente (R1) é aspirado por último, fica mais próximo à válvula seletora de modo que, revertendo-se o fluxo, é a zona que chega primeiro ao detector, percorrendo menor distância $e$, portanto, sofrendo menor dispersão

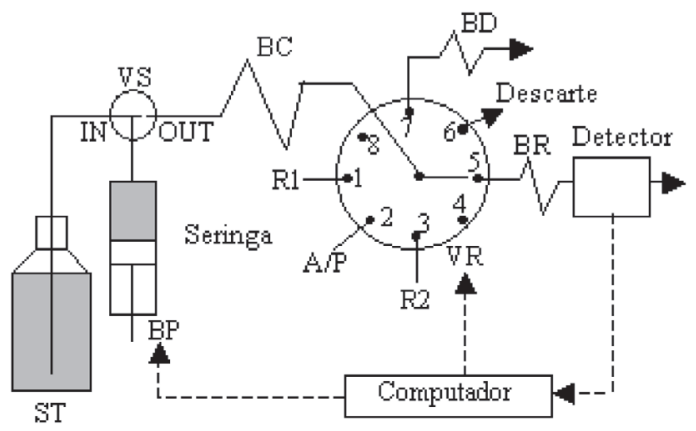

Figura 2. Sistema de injeção seqüencial constituído por Bomba de Pistão (BP) acoplada à seringa de vidro com capacidade de 5,00 mL e válvula solenóide de duas vias (IN e OUT); Bobina Coletora (BC) helicoidal construída com $3 \mathrm{~m}$ de tubo de Teflon com $0,8 \mathrm{~mm}$ de diâmetro interno; Válvula Rotatória Seletora (VR) de 8 portas mostrada na figura com conexão interna entre a porta central e a porta 5; Bobina de Reação (BR) helicoidal construída com $75 \mathrm{~cm}$ de tubo de Teflon com 0,5 mm de diâmetro interno; Bobina de Diluição $(B D)$ helicoidal construída com $1 \mathrm{~m}$ de tubo de polietileno com 1 mm de diâmetro interno; sistema de detecção espectrofotométrica selecionado a $660 \mathrm{~nm}$ nos estudos de determinação de fosfato e em $540 \mathrm{~nm}$ nos estudos de dispersão. Nas análises de fosfato R1 é uma solução de molibdato de amônio 2,5 × $10^{-3}$ ou 1,0 $\times 10^{-2} \mathrm{~mol} \mathrm{~L}^{-1}$ em presença de $\mathrm{HNO}_{3} 0,20 \mathrm{~mol} \mathrm{~L}^{-1}$. R2 é uma solução de ácido ascórbico $2,5 \%(\mathrm{~m} / \mathrm{v})$. A solução transportadora (ST) é água destilada. A solução de amostra elou padrão $(A / P)$ é conectada na porta 2 de $V R$ mensões de $75 \mathrm{~cm}$ de comprimento e $0,50 \mathrm{~mm}$ de diâmetro interno. A bobina de diluição (BD) foi construída com $1 \mathrm{~m}$ de tubo de polietileno com diâmetro interno de $1 \mathrm{~mm}$. Todas as conexões entre os reservatórios de reagentes e padrões com as portas de VR foram feitas com tubos de Teflon de diâmetro interno 0,5 $\mathrm{mm}$ usando adaptadores e anilhas da Upchurch (Oak Harbor, WA, USA). A detecção foi feita com um espectrofotômetro da Micronal modelo B382 (São Paulo, SP, Brasil) com uma cela de fluxo com formato em $\mathrm{U}$ de $10 \mathrm{~mm}$ de caminho ótico e $80 \mu \mathrm{L}$ de volume interno (Hellma GmbH\&Co., Mulheim, Baden, Alemanha). O controle da bomba de pistão e da válvula seletora multiportas foi feito com o software FiaLab 3500 e a aquisição dos dados foi realizada com uma placa PC-LPM-16 da National Instruments (Austin, TX, USA).

Todos os reagentes utilizados foram de grau analítico, adquiridos da Merck (Rio de Janeiro, RJ). Os estudos de dispersão foram efetuados com uma solução de $\mathrm{KMnO}_{4} 6,0$ x $10^{-4} \mathrm{~mol} \mathrm{~L}^{-1}$. As soluções padrão de fosfato foram preparadas nas concentrações 10, 20, 25, 40, 50, 60, 80, 100, 200 e $400 \mathrm{mg} \mathrm{L}^{-1}$ de $\mathrm{P}$ a partir de diluição apropriada de uma solução estoque $1000 \mathrm{mg} \mathrm{L}^{-1}$ preparada dissolvendo-se 4,395 $\mathrm{g}$ de $\mathrm{KH}_{2} \mathrm{PO}_{4}$ em $1 \mathrm{~L}$ de água destilada em balão volumétrico. A determinação espectrofotométrica de fosfato é baseada no uso de dois reagentes, molibdato de amônio (R1) e ácido ascórbico (R2). R1 foi preparado na concentração de 2,5 x 10-3 mol $\mathrm{L}^{-1}$ dissolvendo-se $0,3090 \mathrm{~g}$ de $\left(\mathrm{NH}_{4}\right)_{6} \mathrm{Mo}_{7} \mathrm{O}_{24} \cdot \mathrm{H}_{2} \mathrm{O}$ em pequeno volume de água destilada e $1,3 \mathrm{~mL}$ de $\mathrm{HNO}_{3}$ concentrado, com posterior diluição até o volume total de $100,0 \mathrm{~mL}$ com água destilada. R1 foi também preparado na concentração de $1,0 \times 10^{-2}$ mol $\mathrm{L}^{-1}$ dissolvendo-se $1,236 \mathrm{~g}\left(\mathrm{NH}_{4}\right)_{6} \mathrm{Mo}_{7} \mathrm{O}_{24} \cdot \mathrm{H}_{2} \mathrm{O}$ em balão volumétrico de $100,0 \mathrm{~mL}$ contendo $1,30 \mathrm{~mL}$ de $\mathrm{HNO}_{3}$ concentrado, de modo que em ambas soluções de R1 a concentração final de ácido foi $0,20 \mathrm{~mol} \mathrm{~L}^{-1}$. R2 foi preparado na concentração de $2,5 \%(\mathrm{~m} / \mathrm{v})$, por simples diluição de 2,5 g de ácido ascórbico em água destilada em um balão volumétrico de 100,0 mL. Amostras de refrigerante foram analisadas diretamente, sem tratamento prévio.

\section{Procedimento}

\section{Análise direta}

As etapas descritas a seguir são baseadas no esquema de aparelhagem de injeção seqüencial mostrado na Figura 2. Inicialmente, a bobina coletora (BC) e a bobina de reação (BR), assim como a bobina de diluição (BD), são preenchidas com água destilada, que é a solução transportadora. Os demais tubos conectados em VR são preenchidos com a respectiva solução (reagentes, amostra ou padrão), enquanto os tubos não utilizados são preenchidos com água destilada. A rotina de análise é então iniciada e, com a válvula da seringa (VS) na posição IN, a bomba de pistão aspira 1500 $\mu \mathrm{L}$ de solução transportadora para o interior da seringa a uma vazão de $250 \mu \mathrm{L} \mathrm{s}^{-1}$. A válvula da seringa (VS) é comutada para a posição OUT e VR é posicionada na porta 2 , de onde, a uma vazão de $250 \mu \mathrm{L} \mathrm{s}^{-1}$, se aspira $300 \mu \mathrm{L}$ de solução a ser analisada (branco, padrão ou amostra) para o interior da bobina coletora. A válvula seletora é comutada para a porta 6 e BP dispensa $500 \mu \mathrm{L}$ de solução no descarte auxiliar. Com esse procedimento, a linha de amostragem (porta 2) fica preenchida com solução representativa da solução a ser analisada, evitando a ocorrência de contaminação cruzada (efeito de memória). Em seguida, fixa-se a vazão em 100 $\mu \mathrm{L} \mathrm{s}^{-1}$ e BP aspira seqüencialmente $200 \mu \mathrm{L}$ de R1 da porta $1, \mathrm{X} \mu \mathrm{L}$ de amostra da porta 2 (onde $X=25,50,100$ ou $200 \mu \mathrm{L}$ ) e $200 \mu \mathrm{L}$ de R2 na porta 3. Vale salientar que enquanto a bomba de pistão está aspirando ou dispensando soluções, VR permanece fixa na porta selecionada para evitar variações bruscas de pressão e o aparecimento de bolhas de ar. Finalmente, VR é comutada para a porta 
5, conectando $\mathrm{BC}$ a BR, quando então $\mathrm{BP}$ transporta a zona de amostra em direção ao detector, esvaziando a seringa de modo que a solução transportadora efetue a lavagem do sistema, enquanto o sinal é monitorado e coletado.

Nos estudos de determinação dos coeficientes de dispersão, o procedimento descrito no parágrafo anterior é repetido usando-se a solução de $\mathrm{KMnO}_{4} 6,0 \times 10^{-4} \mathrm{~mol} \mathrm{~L}^{-1}$ na posição de R1, amostra ou R2, enquanto todas as demais portas são preenchidas e conectadas a frascos contendo água destilada. O coeficiente de dispersão $(D)$ foi calculado pela expressão ${ }^{8} D=A^{0} / A$, onde $A^{0}$ é a absorbância da solução de $\mathrm{KMnO}_{4} 6,0 \times 10^{-4} \mathrm{~mol} \mathrm{~L}^{-1} \mathrm{e} A$ é a absorbância lida no máximo de pico após a injeção e processamento da mesma solução no sistema SIA.

\section{Diluição em linha}

A rotina de análise é iniciada com BP aspirando $2000 \mu \mathrm{L}$ de solução transportadora para o interior da seringa a uma vazão de $250 \mu \mathrm{L} \mathrm{s}^{-1}$. Em seguida, a VS é comutada para a posição OUT e RV é posicionada na porta 2 , de onde, a uma vazão de $250 \mu \mathrm{L} \mathrm{s}^{-1}$, se aspira $300 \mu \mathrm{L}$ de solução a ser analisada (branco, padrão ou amostra) para o interior de BC. A válvula seletora é comutada para a porta 6 e BP dispensa $500 \mu \mathrm{L}$ de solução no descarte auxiliar. A partir daí fixa-se a vazão em $100 \mu \mathrm{L} \mathrm{s}^{-1}$ e BP aspira $200 \mu \mathrm{L}$ de amostra da porta 2 , dispensando em seguida $320 \mu \mathrm{L}$ de solução de BC para bobina de diluição (BD) conectada na porta 7 de VR. Com isso, a região frontal da zona de amostra (região mais concentrada) é transferida para a bobina de diluição, estabelecendo um gradiente de concentração no qual os elementos de fluido mais diluídos ficam posicionados na região de tubo mais próxima da válvula seletora. ${ }^{9,10}$ Em seguida, BP aspira seqüencialmente $200 \mu \mathrm{L}$ de R1 da porta $1,25 \mu \mathrm{L}$ de amostra diluída da porta 7 e $200 \mu \mathrm{L}$ de $\mathrm{R} 2$ na porta 3. RV é comutada para a porta 5 e BP dispensa $1500 \mu \mathrm{L}$ de solução transportadora, de modo que a zona de reação é injetada em direção ao detector, gerando o sinal transiente típico dos sistemas de injeção em fluxo. Finalmente, VR é comutada para a porta 7 e BP esvazia a seringa a uma vazão de $250 \mu \mathrm{L} \mathrm{s}^{-1}$, limpando BD e deixando todo o sistema pronto para efetuar a próxima análise.

\section{RESULTADOS E DISCUSSÃO}

A reação entre fosfato e molibdato de amônio em meio ácido segue uma relação estequiométrica 1:12 entre fósforo e molibdênio, conforme mostrado abaixo:

$7 \mathrm{H}_{3} \mathrm{PO}_{4}+12\left(\mathrm{NH}_{4}\right)_{3} \mathrm{Mo}_{7} \mathrm{O}_{24}+51 \mathrm{H}^{+} \rightarrow 7\left(\mathrm{NH}_{4}\right)_{3} \mathrm{PO}_{4} \cdot 12 \mathrm{MoO}_{3}+$ $51 \mathrm{NH}_{4}^{+}+36 \mathrm{H}_{2} \mathrm{O}$

$\mathrm{O}$ produto é amarelo e apresenta baixa absortividade molar, de modo que um agente redutor, geralmente ácido ascórbico, é usado para reduzir o $\mathrm{Mo}(\mathrm{VI})$ a $\mathrm{Mo}(\mathrm{V})$, formando então um complexo azul, conhecido como azul de molibdênio, que por sua vez apresenta elevada absortividade molar em $660 \mathrm{~nm} .{ }^{11}$

Assim como nos demais sistemas de análise em fluxo, a magnitude do sinal analítico em sistemas SIA depende fortemente do volume de amostra. Volumes maiores implicam em maior sinal, uma vez que a dispersão da zona de amostra diminui. ${ }^{3,8}$ Em sistemas de fluxo nos quais o reagente é adicionado por confluência, a injeção de um elevado volume de amostra (volume infinito) gera um sinal transiente cujo ponto de máximo se aproxima em magnitude ao valor correspondente ao estado estacionário, com um coeficiente de dispersão tendendo a um valor mínimo, definido pela razão entre as vazões de solução transportadora e do reagente ${ }^{6}$. Em sistemas de fluxo com uma única linha de transmissão conduzindo o reagente, a injeção de volumes elevados de amostra pode causar a formação de picos duplos, devido à falta de reagente nas regiões centrais da zona de amostra. ${ }^{6,12}$ No sistema SIA, entretanto, estas características são obedecidas apenas parcialmente,

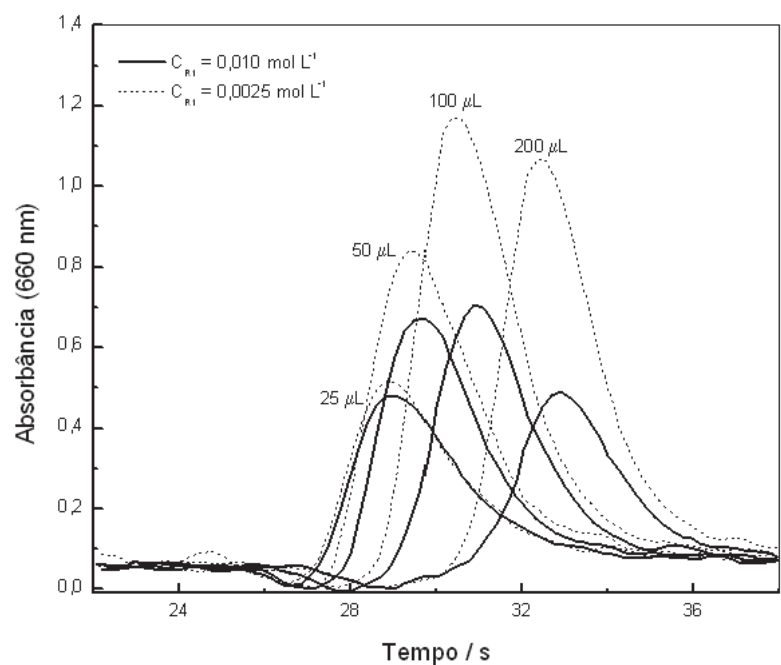

Figura 3. Influência do volume de amostra (solução $10 \mathrm{mg} \mathrm{L}^{-1}$ de $\mathrm{PO}_{4}^{3-}$ - P) aspirada entre duas zonas de $200 \mu \mathrm{L}$ de R1 e R2, sendo que as concentrações

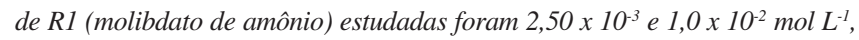
enquanto a concentração de ácido ascórbico ( $R 2)$ foi mantida fixa em 2,50\% $(m / v)$

como mostra a Figura 3, que ilustra o efeito do volume de amostra aspirado entre os dois reagentes, bem como o efeito da concentração do reagente molibdato de amônio (R1) sobre o sinal analítico de uma solução de fosfato $10 \mathrm{mg} \mathrm{L}^{-1}$ (em P). Utilizando R1 com concentração $2,50 \times 10^{-3} \mathrm{~mol} \mathrm{~L}^{-1}$ observa-se que o aumento de sinal ocorre aumentando-se o volume de amostra de 25 para $100 \mu \mathrm{L}$. Entretanto, aumentando o volume para $200 \mu \mathrm{L}$ observa-se uma pequena diminuição do sinal apesar do menor coeficiente de dispersão, indicando que a zona de amostra não está recebendo reagente em quantidade suficiente. Um simples cálculo estequiométrico envolvendo o número de moles de $\mathrm{P}$ e de Mo injetados no sistema SIA (Tabela 1) mostra que somente até o volume de amostra de $100 \mu \mathrm{L}$ existe excesso de reagente. Entretanto, a diminuição da magnitude do sinal observada injetando-se $200 \mu \mathrm{L}$ de amostra é explicada pelo menor grau de sobreposição das zonas em relação ao que se obtém com menores volumes de amostra.

Avaliando-se os resultados obtidos com a solução de molibdato de amônio $1,0 \times 10^{-2} \mathrm{~mol} \mathrm{~L}^{-1}$ pode-se verificar que o sinal analítico é sistematicamente maior do que observado para a solução mais diluída do reagente (Figura 3), especialmente no caso do volume de amostra de $200 \mu \mathrm{L}$. Este fato é explicado pela maior disponibilidade de reagente, muito embora aumentando-se o volume de amostra de 50 para $100 \mu \mathrm{L}$ já se pode observar que a formação de produto é limitada, uma vez que apesar de se dobrar o número de moles de $\mathrm{P}$ na

Tabela 1. Número de moles de fósforo em função dos volumes de uma solução $10 \mathrm{mg} \mathrm{L}^{-1}$ injetados no sistema em comparação com o número de moles de Mo necessários para obedecer a relação estequiométrica da reação. Considerando que o volume de R1 foi sempre $200 \mu \mathrm{L}$, o número de moles de Mo injetados foram $50 \times 10^{-8} \mathrm{e}$ $200 \times 10^{-8}$ para R1 de concentrações 2,5 e $10,0 \times 10^{-3} \mathrm{~mol} \mathrm{~L}^{-1}$, respectivamente

\begin{tabular}{lcc}
\hline $\begin{array}{l}\text { Volume de } \\
\text { amostra/ } \mu \mathrm{L}\end{array}$ & moles de P x 108 & $\begin{array}{c}\text { moles de Mo } \\
\text { necessários } \times 10^{8}\end{array}$ \\
\hline 25 & 0,806 & 9,67 \\
50 & 1,61 & 19,3 \\
100 & 3,23 & 38,8 \\
200 & 6,45 & 77,4 \\
\hline
\end{tabular}


presença de excesso de Mo, o sinal, no máximo de pico, teve um aumento de apenas $44 \%$. Esta limitação pode ser explicada pela baixa sobreposição das zonas de reagente e amostra, conforme será discutido a seguir.

O estudo de sobreposição das zonas foi realizado injetando um corante (solução de $\mathrm{KMnO}_{4} 6,0 \times 10^{-4} \mathrm{~mol} \mathrm{~L}^{-1}$ ) em uma solução transportadora (água destilada), seguindo o procedimento de análise, ou seja, o corante é colocado na porta referente a um dos reagentes ou amostra, enquanto as outras portas são conectadas ao reservatório de
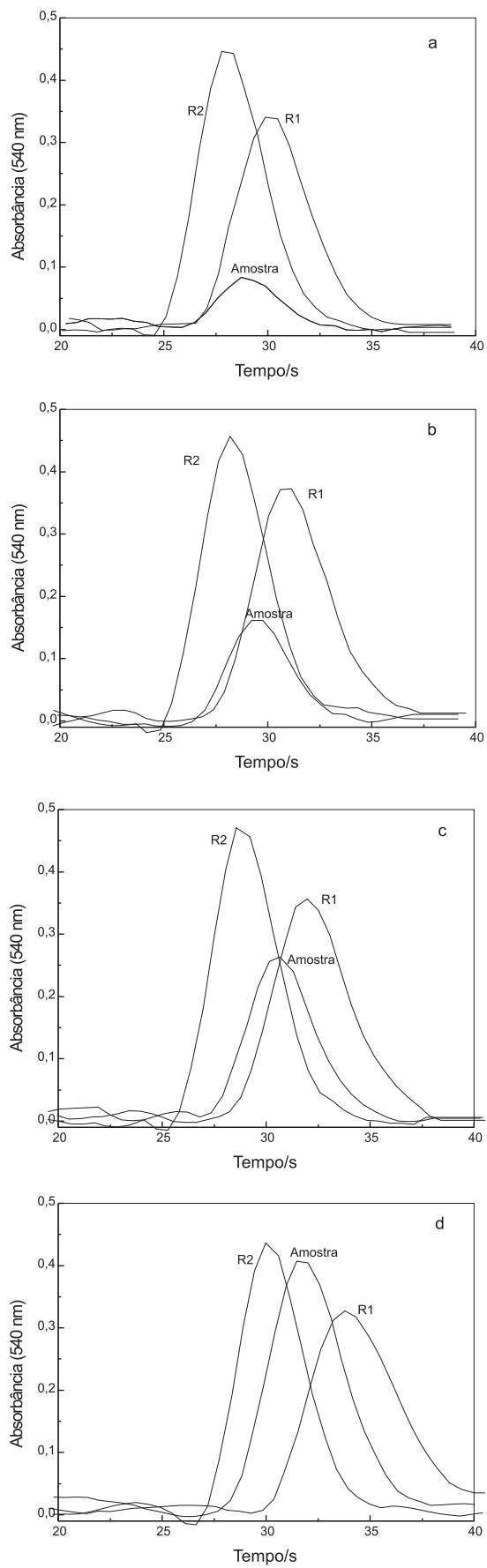

Figura 4. Sobreposição da zona de amostra com as zonas de R1 e R2 em função do volume de amostra de (a) 25, (b) 50, (c) 100 e (d) $200 \mu \mathrm{L}$. Os valores do grau de sobreposição $(P)$ entre R1 e R2 foram de 0,73; 0,61;0,57 e 0,49 para volumes de amostra de 25, 50, 100 e $200 \mu \mathrm{L}$, respectivamente, enquanto para estes mesmos volumes, os coeficientes de dispersão $(D)$ da zona de amostra no máximo de pico foram 6,58; 3,41; 2,12 e 1,34 solução transportadora. Em seguida troca-se a posição do corante com a de outro reagente ou amostra e repete-se o procedimento. No presente experimento três ciclos são realizados, colocando-se a solução de $\mathrm{KMnO}_{4}$ na posição de R1, amostra e R2. Finalmente sobrepõem-se os três sinais transientes, conforme é mostrado na Figura 4, a qual mostra claramente que para volumes de amostra de 25 e $50 \mu \mathrm{L}$ (Figura 4a e 4b) o gradiente de concentração da amostra está completamente sobreposto pela sobreposição dos gradientes de R1 e R2. No caso de volume de $100 \mu \mathrm{L}$ (Figura 4c), o máximo de pico do gradiente de concentração da amostra coincide com o ponto de isodispersão, com um coeficiente de dispersão igual a 2 , o que significa que no ponto de mais alta concentração da amostra houve uma diluição na razão de 1:1 com a solução de reagentes R1 e R2. Por outro lado, quando o volume de amostra injetado é de $200 \mu \mathrm{L}$ (Figura 4d), o coeficiente de dispersão da zona de amostra nos elementos de fluido correspondentes ao máximo de pico é 1,3, indicando um baixo grau de sobreposição desta região da zona de amostra com as duas zonas de reagente. Conclui-se que em condições de baixa sobreposição das zonas é necessário usar uma elevada concentração do reagente, no sentido de satisfazer a relação estequiométrica da reação em todos os elementos de fluido da zona de amostra. No sentido de minimizar a dispersão da amostra, utilizando-se volumes maiores e ainda obtendo-se efetiva sobreposição com os reagentes, métodos associando injeção seqüencial com conceitos de amostragem binária ${ }^{13}$ e fluxo monossegmentado ${ }^{14-16}$ têm sido desenvolvidos e relatados na literatura.
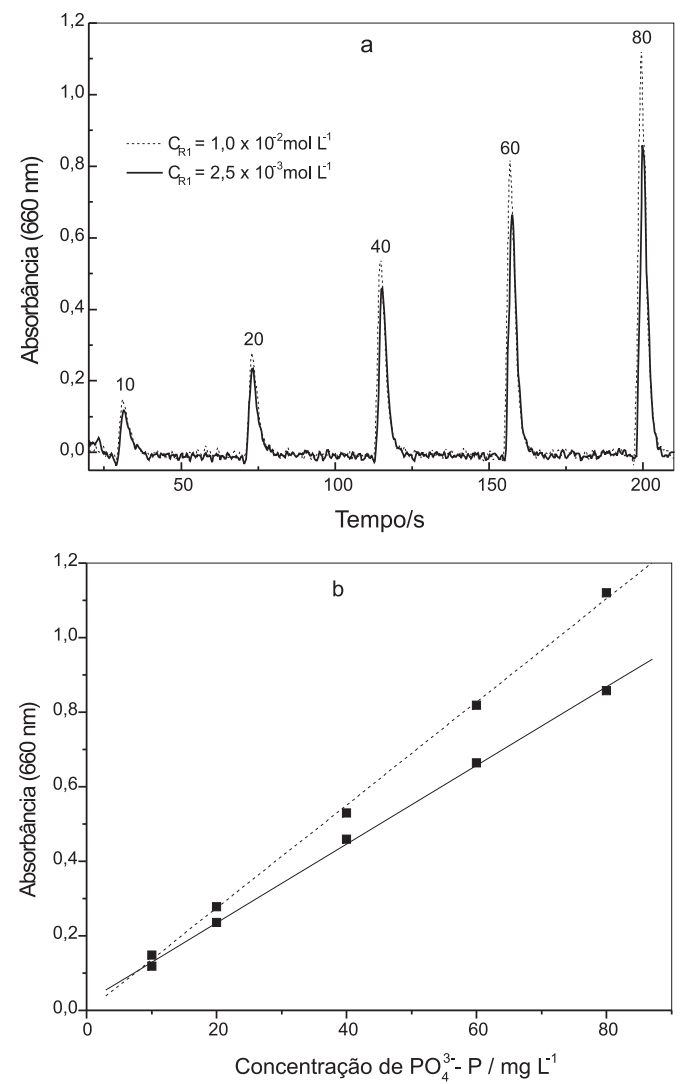

Figura 5. Registro de sinais transientes (a) obtidos pela injeção de $50 \mu \mathrm{L}$ de soluções padrão de fosfato entre $200 \mu \mathrm{L}$ de $R 1\left(0,25\right.$ e $\left.1,0 \times 10^{-2} \mathrm{~mol} \mathrm{~L}^{-1}\right) \mathrm{e}$ $R 2$. Os números sobre cada pico indicam a concentração em $\mathrm{mg} \mathrm{L}^{-1}$ de fósforo. A curva analítica (b) obtida com R1 1,0 × $10^{-2} \mathrm{~mol} \mathrm{~L}^{-1}$ ajustou-se à equação linear $A_{660}=(0,0138 \pm 0,0003) C_{P}-(0,00 \pm 0,01)$ com $r=0,9992$, enquanto para R1 2,5 × $10^{-3} \mathrm{~mol} \mathrm{~L}^{-1}$ a equação obtida foi $A_{660}=(0,0106 \pm 0,0002) C_{P}+$ $(0,02 \pm 0,01)$, com $r=0,9994$, onde $A_{660}$ é a absorbância lida no máximo de pico e $C_{P}$ a concentração de fosfato expressa em $\mathrm{mg} \mathrm{L}^{-1}$ de $P$ 
Adotando-se o volume de amostra de $50 \mu \mathrm{L}$, curvas analíticas foram construídas usando as duas concentrações de R1 (Figura 5a e 5b). Usando-se R1 com concentração de $1,0 \times 10^{-2} \mathrm{~mol} \mathrm{~L}^{-1}$ se obtém sensibilidade cerca de $30 \%$ maior do que em relação ao R1 $2,5 \times 10^{-3} \mathrm{~mol} \mathrm{~L}^{-1}$, o que pode ser explicado por fatores cinéticos devido a maior disponibilidade de molibdato na zona de reação. Para o volume de amostra de $50 \mu \mathrm{L}$ e R1 com concentração $1,0 \mathrm{x}$ $10^{-2} \mathrm{~mol} \mathrm{~L}^{-1}$, os limites de detecção $(L O D=3,3 \mathrm{~s} / \mathrm{S})$ e determina-

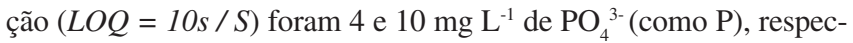
tivamente, onde $s$ é o desvio padrão dos resíduos da regressão linear e $S$ a inclinação da curva analítica. ${ }^{11}$ Outra figura de mérito importante em métodos de análise em fluxo é o consumo de reagentes, sendo que o consumo de R1 nas concentrações 0,25 e $1,0 \times 10^{-2}$ mol $\mathrm{L}^{-1}$ foi de 0,618 e 2,47 $\mathrm{mg}$ por análise, respectivamente, enquanto o consumo de ácido ascórbico foi de 5,0 mg.

Como exemplo de aplicação do método a amostras concentradas, fez-se a determinação de fosfato em refrigerante após diluição em linha, explorando o conceito de re-amostragem, ou seja, analisando-se uma porção de solução da amostra que já tenha sido submetida a processos de dispersão no sistema. A Figura 6 ilustra uma seqüência de injeções de soluções de fosfato com concentrações entre 50 e $400 \mathrm{mg} \mathrm{L}^{-1}$ em P, seguindo-se a injeção da amostra. A concentração média de fosfato em dez amostras de refrigerante foi de $218 \pm 9 \mathrm{mg} \mathrm{L}^{-1}$ em P. O desvio padrão relativo para uma mesma amostra (repetitividade) foi da ordem de $3 \%(n=10)$. A frequiência de amostragem foi de 70 determinações por hora, o que é adequado para monitoramento de processos, uma vez que a diluição da amostra e lavagem do sistema é feita automaticamente.

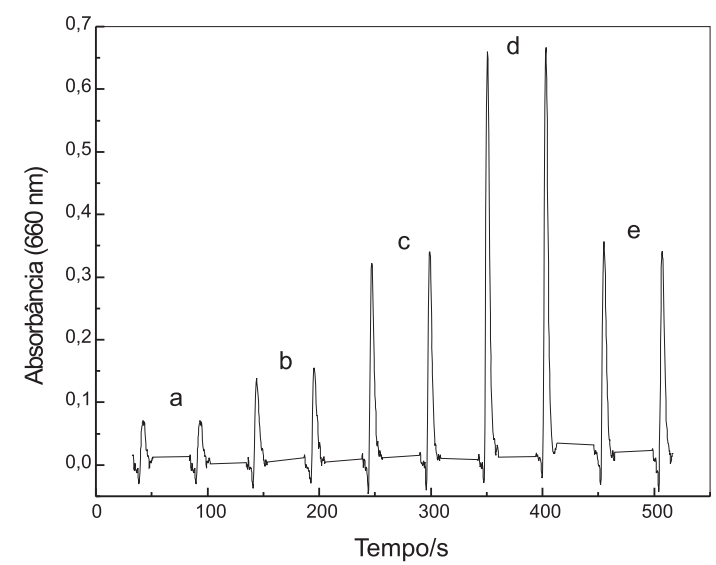

Figura 6. Registro de sinais transientes obtidos para soluções de fosfato (a) 50, (b) 100, (c) 200 e (d) $400 \mathrm{mg} \mathrm{L}^{-1}$ em P, em comparação com a amostra de refrigerante (e). Os dados experimentais se ajustaram à equação $A_{660}=$ $(0,0017 \pm 0,0001) C_{P}-(0,016 \pm 0,007)$, com $r=0,9997$. Todas as soluções foram submetidas ao mesmo processo de amostragem de $200 \mu \mathrm{L}$ de amostra concentrada, injeção de $320 \mu \mathrm{L}$ de solução transportadora na bobina de diluição e re-amostragem de $25 \mu \mathrm{L}$ desta bobina entre as duas zonas de 200 $\mu L$ de $R 1\left(1,0 \times 10^{-2} \mathrm{~mol} \mathrm{~L} L^{-1}\right)$ e R2

\section{CONCLUSÃO}

Este experimento é ministrado na disciplina de Química Analítica Instrumental do curso de graduação em Química do Instituto de Química da Universidade de São Paulo, bem como na disciplina Análise por Injeção em Fluxo: Princípios e Aplicações do programa de Pós-Graduação da área de Química Analítica da mesma instituição. Com o experimento se demonstra a compatibilidade da análise por injeção seqüencial com automação, ilustrando a possibilidade de modificar parâmetros instrumentais do método, tais como diferentes volumes de amostra e incorporação de diluição em linha, sem a necessidade de se re-configurar mecanicamente o sistema. Discute-se que, com programação apropriada, o sistema é capaz de automatizar a análise ao invés de simplesmente mecanizála. A introdução de sub-rotinas que são acionadas por valores limites de sinal analítico permite que amplas faixas de concentração sejam monitoradas sob diferentes condições de análise, sem intervenção do analista, o que é uma importante característica para atender às necessidades de monitoramento automático de processos. ${ }^{17,18}$ Por outro lado, o experimento demonstra também os cuidados que são necessários para desenvolver o método aplicável a amostras concentradas, visando manter o excesso de reagente na zona de amostra, uma dificuldade inerente a configuração de linha simples dos sistemas de injeção seqüiencial.

\section{AGRADECIMENTOS}

À FAPESP e ao CNPq pelos auxílios financeiros e bolsa de estudo concedidos.

\section{REFERÊNCIAS}

1. Ruzicka, J.; Anal. Chim. Acta 1992, 261, 3.

2. Ruzicka, J.; Marshall, G. D.; Anal. Chim. Acta 1990, 237, 329.

3. Gubelli, T.; Christian, G. D.; Ruzicka, J.; Anal. Chem. 1991, 63, 2407.

4. Christian, G. D.; Analyst 1994, 119, 2309.

5. Bergamin F., H.; Reis, B. F.; Zagatto, E. A. G.; Anal. Chim. Acta 1978, 97, 427.

6. Reis, B. F.; Giné, M. F.; Kronka, E. A. M.; Quim. Nova 1989, 12, 82.

7. Reis, B. F.; Jacintho, A. O.; Mortatti, J.; Krug, F. J.; Zagatto, E. A. G.; Bergamin F., H.; Pessenda, L. C. R.; Anal. Chim. Acta 1981, 123, 221.

8. Ruzicka, J.; Hansen, E. H.; Flow Injection Analysis, $2^{\text {nd }}$ ed., Wiley: New York, 1988.

9. Baron, A.; Guzman, M.; Ruzicka, J.; Christian, G. D.; Analyst 1992, 117, 1839.

10. Oliveira, P. C. C.; Masini, J. C.; Analyst 1998, 123, 2085.

11. Christian, G. D.; Analytical Chemistry, $6^{\text {th }}$ ed, Wiley: New York, 2004.

12. Zagatto, E. A. G.; Rocha, F. R. P.; Martelli, P. B.; Reis, B. F.; Pure Appl. Chem. 2001, 73, 45.

13. Reis, B. F.; Giné, M. F.; Zagatto, E. A. G.; Lima, J. L. F. C.; Lapa, R.; Anal. Chim. Acta 1994, 293, 129.

14. Pasquini, C.; de Oliveira, W. A.; Anal. Chem. 1985, 57, 2575.

15. Vieira, J. A.; Raimundo, I. M.; Reis, B. F.; Zagatto, E. A. G.; Lima, J. L. F. C.; Anal. Chim. Acta 1998, 366, 257.

16. Silva, M. S. P.; Masini, J. C.; Anal. Chim. Acta 2002, 466, 345.

17. Masini, J. C.; Baxter, P. J.; Detwiller, K. D.; Christian, G. D.; Analyst 1995, $120,1583$.

18. Trevisan, M. G.; Poppi, R. J.; Quim. Nova 2006, 29, 1065. 